\title{
Personal Problems and English Teachers: Are They Always Bad?
}

\author{
Muhd Khudri Johari (Corresponding author) \\ Department of Campus Lifestyles \\ Universiti Kuala Lumpur - Malaysian Institute of Aviation Technology \\ 43800, Selangor, Malaysia \\ E-mail: mdkhudri@miat.unikl.edu.my
}

Nur Zaimah Jamil

Department of Language and Literacy Education,

Faculty of Education, Malaya University

50603 Kuala Lumpur, Malaysia

Received: 30-09-2013

doi:10.7575/aiac.ijalel.v.3n.1p.163
Accepted: 07-11-2013

Published: 01-01-2014

\begin{abstract}
Personal problems involve things that are difficult to deal with, felt or experienced by certain people; in this particular study, Malaysian English language teachers. The relationship between personal problems and teaching reflection practice is researched quantitatively as there is a significant concern in the current education system that English language teachers are not doing well in educating the current generation, hence the professional developments needed to be carried out (Masilamani, et al., 2011; Schleicher, 2011; Schleicher, 2011). Based on the authors' readings, there has yet been any research regarding this matter done in the Malaysian context. Hence, different types of personal problems have been identified via a validated questionnaire specifically made for this purpose. 45 English language teachers participated in this action research; all of whom are currently teaching in the same district in southern Negeri Sembilan, Malaysia. Although the results showed that personal problems affected teaching reflection practice negatively, it is hoped that future research will look into how teachers can utilize their problems as personal intrinsic motivators to obtain positive reinforcements and achieve success in their careers.
\end{abstract}

Keywords: personal problems, teaching reflection, Ideal Personal Problem - Teaching Reflection (PPRT) Inventory

\section{Introduction}

In this study, these selected teachers are having difficulties in conducting, managing, reviewing, and later assessing their teaching reflections because of several obstacles, including financial and marital status. This phenomenon is enforced by the exam-oriented nature of education system in this country that has been criticized by the public (Rajaratenam, 2012). Therefore, this research aims to determine how far personal problems really affect English language teachers' teaching reflection practice here in Malaysia.

In order to properly carry out teaching reflection processes, they must first know exactly what to "repair". The Ideal PPRT inventory will point out several problems from case studies and researches; the teachers must carefully observe the ones that they are facing currently. Guidance and support are critically needed to ensure they do not go off-track, hence brief definitions or explanations will be arranged in the inventory. The support may also come from trusted colleagues or reputable leaders within their departments who have prior knowledge regarding teaching reflections. Peercoaching in TEFL/TESL programmes has been proven to be beneficial and improving teachers' performance, resulting in Silvana and Rhoda (Vacilotto \& Cummings, 2007) to recommend the implementation of peer-coaching in Brazil's national teacher development programmes.

\section{Literature Review}

\subsection{Personal Problems}

In 1979, Anthony P. Mattaliano, a Professor cum Principal from Connecticut pointed out that in reality, teachers are still human beings. Naturally, they would have personal problems and it is very crucial for all teachers' supervisors to identify and assist in solving their teachers' personal problems (Mattaliano, 1979). This is simply because Mattaliano also stressed that teaching is a very personal act, hence whatever happens usually stays in the classrooms. Therefore, the relationship between the teachers and their supervisors has been distinguished as highly necessary to rectify any situation that involves personal problems. 
Specifically for elementary schools teachers and beginning secondary school teachers, Simon Veenman from Catholic University of Nijmegen has determined several personal problems such as reality shock or culture shock, change of attitudes, and their relation with supervisors/administrators, colleagues and parents (Veenman, 1984). This research was not only concentrating on the teachers in one country. The data collection for his study took around 15 years (from 1961 until 1976). Specifically, he gathered the data from schools in USA, UK, Puerto Rico, West Germany, Australia, Netherlands, Canada, Switzerland, Austria, and Finland (Veenman, 1984).

Indeed, culture plays an important factor for anyone who is having personal problems. Defined as 'a phenomenon at the group, institutional, or societal level, even though it has strong relevance for predicting individuals' behaviours, researchers have proven that there is a strong link between job satisfaction-job performance relationship and cultures (Ng, Sorensen, \& Yim, 2009). Even though their study did not focus solely on teachers, they have at least found out that the respondents' job satisfaction-job performance relationship varied according to the different cultures they live in.

Particularly in Malaysia, the cultural values differ as much as the cultural diversity that exists within the country's population. As explained by Sharan and Mazanah (2000), Malaysians have five general values; collectivistic, hierarchical, relationship oriented, face and religious. These positive values are indicating that supposedly, Malaysian citizens would have no problems living their life, including working here as teachers.

The fact is though, it is not. While some may have no personal problems because of cultures, other teachers have been found to suffer with the increasing number of resignation, stress and burnout (Masilamani, et al., 2011) because of being Malay. The same study also concluded that the second factor of the rising number was the absence of superiors' support. Goris (2003) stressed that the crucial part is the trust in superiors would moderate the relationship between the individual-job congruence condition with both job performance and job satisfaction (Goris, Vaught, \& Pettit, 2003).

Therefore, administrators must find alternatives or approaches that can help to improve on the matter of teachers wanting to leave their working place or worse, their teaching profession. In particular, schools must provide high standards of caring climate and procedural justice and reduce tolerance of organizational misbehaviour (ShapiraLishchinsky \& Rosenblatt, 2009).

Regarding teachers' personal demographic information, school administrators need to facilitate the knowledge and keep track of issues which may be deemed too sensitive for certain teachers, such as religion or cultural matters. With the five Malaysian values (Merriam \& Mohamad, 2000) explained previously, they need to inculcate the strength of unity within the diversity among the teachers under their supervision in order to maximize teachers' positive attitudes and perceptions towards the school. With these in mind, teachers would naturally become more socialized and committed, making them less inclined to consider quitting their profession (Shapira-Lishchinsky \& Rosenblatt, 2009).

In this respect, it can also be said that school administrators should be servant leaders to improve job satisfaction, which in turn contributes to the effective work of their teachers and indirectly making them happier to stay (Cerit, 2009). With regards to the effective teaching and learning environments related to teachers' superiors, Organization of Economic Co-operation and Development (OECD) did a study on 24 countries (including Malaysia as one of the seven nonmembers of OECD countries). Schleicher (2011) pointed out several domains which are imperative for school administrators to consider; Supporting Effective Teaching through Appraisal and Feedback, Improving Teaching Practice and Shaping the Development of Teachers through Effective School Leadership (Schleicher, 2011). Even now, it has been proven that personal problems still exist and affecting teachers in schools (Nakata, 2010).

\subsection{Ideal PPRT Inventory}

Other researchers keep on confirming that personal problems are affecting teachers' performance in general, which after a period of time causes them to slowly deteriorating in motivation, cognitive conflict and social construction (Adey, et al., 2004). Adey's CA Approach has been designed solely for this purpose; to be used as a tool for professional development. Even though it was originally tailored for students, it has been adapted and implemented by various programmes in different countries. For instance, Dusan Krnel from University of Lublijana, Slovenia and personnel from Palestinian Education Authority have introduced the Cognitive Acceleration (CA) Approach in schools in their respective countries. It seems that other countries which have started implementing this approach have gotten positive results in seeing their students' progress in professional development (Adey, et al., 2004). With all these positive and encouraging results from different countries, it is in the authors' optimistic perception that the CA Approach will also be efficient if it is tailored and implemented for the teachers instead of the students.

Responding to Adey's recommendation, this approach has been adapted and combined with another two adapted sets of validated questionnaires for personal problems to form the Ideal PPRT Inventory. Both sets are referring to Inventory of Interpersonal Problems (IIP) (Horowitz, et. al) and Personal Problem Inventory or "15PPI" (Cash, Begley, McCown, and Weise, 1975). They will be used as the primary reference for the construction of the specific inventory for this study, which will be using Lin Norton's The Ideal *** Inventory (2001) as the main framework. Together with Zeichner and Liston's Reflection Model (1996) as the main instrument for teaching reflection, the main objective of this study is to find out and confirm whether there is a significant relationship between personal problems and teaching reflection practice among English language teachers in Malaysia.

\section{Methodology}

\subsection{Research Design}

This research is using the concept of Classroom Action Research which involves English Language teachers in their respective classrooms. Common issues regarding their teaching reflections have been examined during the interview 
sessions outside classrooms (Ary, Jacobs, \& Sorensen, 2006). Practical Action Research method has been chosen to determine the effects of the personal problems faced by these teachers in carrying out teaching reflection activities at their workplace (Creswell, 2008). The area of focus of this action research will only be on the personal problems faced by these teachers as the major crisis for teaching reflection practice, which will also reflect on what are the possible causes for their identified personal problems. After the data has been analysed, an action plan will be devised to solve the problems.

\subsection{Data Collection}

A research was conducted on selected English language teachers from a secondary school in Rembau district in Negeri Sembilan, Malaysia. They were pre-selected after a few observations made by the authors visually indicated that these teachers were getting more negative responses and feedbacks from their own students during the school period occasionally. Meetings and appointments were made for all these teachers.

All selected teachers were called beforehand to arrange the most suitable time and place of their own preferences within their office hours and workplace to ensure their utmost willingness and readiness to participate in this research. If by any reason the selected teacher was unwilling to participate, the authors would find another replacement either from the same or another secondary school within the same district to increase the validity and reliability of the data. They would then meet with the authors to take some time to answer the questionnaire provided. Every teacher was given 30 minutes to answer all the 15 items provided in the questionnaire. These entire processes were repeated for the other secondary school teachers in Rembau district.

\section{Results and Discussion}

\subsection{Results}

The outputs were arranged in Table. 1 with their respective data analysis and the items from the Ideal PPRT Inventory were interpreted according to the authors' intended contexts and objectives to indicate whether the main objectives of this research had been achieved or not.

Table 1. Personal Problems

\begin{tabular}{lcr}
\hline & Frequency & Percent \\
\hline One Personal Problem & 5 & 11.1 \\
\hline Two Personal Problems & 13 & 28.9 \\
\hline $\begin{array}{l}\text { Three Personal } \\
\text { Problems }\end{array}$ & 27 & 60.0 \\
\hline Total & 45 & 100.0 \\
\hline
\end{tabular}

Next, the numbers recorded show what are the possible causes or reasons for their personal problems and the statistics according to how many personal problems that they have. All 15 items in the inventory will be analysed separately.

\subsection{Personal Problems}

Based on the data accumulated from the teachers, there were 11 different personal problems that have been identified from the questionnaires. The frequencies for every personal problem have been calculated to establish which one has been experienced by most number of teachers.

Table 2. Cause 1

\begin{tabular}{lcc}
\hline Personal problems & Frequency & Percent \\
\hline None & 0 & 0.0 \\
\hline Financial & 6 & 13.3 \\
\hline $\begin{array}{l}\text { Spouses/Romantic } \\
\text { Relationship }\end{array}$ & 16 & 35.6 \\
\hline Family Matters & 6 & 13.3 \\
\hline Employer & 2 & 4.4 \\
\hline Peers/Colleagues & 2 & 4.4 \\
\hline Working & 3 & 6.7 \\
Environment & & \\
\hline KPI & 3 & 6.7 \\
\hline Knowledge of & 1 & 2.2 \\
Content & & \\
\hline Students & 3 & 6.7 \\
\hline Postgraduate Studies & 2 & 4.4 \\
\hline Health & 1 & 2.2 \\
\hline Total & 45 & 100.0 \\
\hline
\end{tabular}


Table 3. Cause 2

\begin{tabular}{lcc}
\hline Personal problems & Frequency & Percent \\
\hline None & 5 & 11.1 \\
\hline Financial & 7 & 15.6 \\
\hline $\begin{array}{l}\text { Spouses/Romantic } \\
\text { Relationship }\end{array}$ & 10 & 22.2 \\
\hline Family Matters & 3 & 6.7 \\
\hline Employer & 1 & 2.2 \\
\hline Peers/Colleagues & 4 & 8.9 \\
\hline $\begin{array}{l}\text { Working } \\
\text { Environment }\end{array}$ & 5 & 11.1 \\
\hline KPI & 1 & 2.2 \\
\hline $\begin{array}{l}\text { Knowledge of } \\
\text { Content }\end{array}$ & 3 & 6.7 \\
\hline Students & 2 & 4.4 \\
\hline $\begin{array}{l}\text { Postgraduate } \\
\text { Studies }\end{array}$ & 2 & 4.4 \\
\hline Health & 2 & 4.4 \\
\hline Total & 45 & 100.0 \\
\hline
\end{tabular}

Table 4. Cause 3

\begin{tabular}{lcc}
\hline Personal problems & Frequency & Percent \\
\hline None & 18 & 40.0 \\
\hline Financial & 2 & 4.4 \\
\hline $\begin{array}{l}\text { Spouses/Romantic } \\
\text { Relationship }\end{array}$ & 1 & 2.2 \\
\hline Family Matters & 4 & 8.9 \\
\hline Employer & 2 & 4.4 \\
\hline Peers/Colleagues & 3 & 6.7 \\
\hline $\begin{array}{l}\text { Working } \\
\text { Environment }\end{array}$ & 1 & 2.2 \\
\hline KPI & 4 & 8.9 \\
\hline $\begin{array}{l}\text { Knowledge of } \\
\text { Content }\end{array}$ & 6 & 13.3 \\
\hline Students & 1 & 2.2 \\
\hline Health & 3 & 6.7 \\
\hline Total & 45 & 100.0 \\
\hline
\end{tabular}

Although the data for the causes have been classified separately (Cause 1, Cause 2, and Cause 3), it does not necessarily mean that one cause has stronger effects compared to the other one or two. For example, Respondent 1, who has two personal problems, wrote that his/her Cause 1 is "Financial" and Cause 2 is "Employer". From the authors' point of view, it simply means that Respondent 1 has two causes for his/her personal problems. Literally, Cause 1 does not necessarily mean that it has a higher impact on the teaching reflection practice of the teachers compared to Cause 2 . The causes are stated by respondents to indicate what kind of real-life personal problems that they were experiencing at that time. In short, the causes listed by the respondents directly reflect what their actual personal problems are and cannot be perceived as a kind of measurement.

\subsection{Interpretation of Data}

\subsubsection{Interpretation}

Except for Item 3, 6, 9, and 13, all the items in the Ideal PPRT Inventory will be interpreted directly (not as reversed items). In other words, the whole idea of whether personal problems affect teachers' teaching reflection practice or not 
will be determined by the total number of responses given for all 15 items. As a result, these are the indicators suggested by the authors;

Table 5. Data Interpretation of the Ideal PPRT Inventory

\begin{tabular}{|c|c|}
\hline Respond & Result \\
\hline $\begin{array}{l}\text { Totally Agree } \\
\text { or } \\
\text { Agree } \\
\text { (Positively-skewed distributions) }\end{array}$ & $\begin{array}{l}\text { Personal problems affect teachers' teaching reflection } \\
\text { practice. (There is a significant relationship between } \\
\text { personal problems and teaching reflection practice.) }\end{array}$ \\
\hline $\begin{array}{l}\text { Neutral } \\
\text { or } \\
\text { Disagree } \\
\text { or } \\
\text { Totally Disagree } \\
\text { (Symmetrical or negatively-skewed distributions) }\end{array}$ & $\begin{array}{l}\text { Personal problems } \text { do not affect teachers' teaching } \\
\text { reflection practice. (There is a significant relationship } \\
\text { between personal problems and teaching reflection } \\
\text { practice.) }\end{array}$ \\
\hline
\end{tabular}

\subsubsection{Positively-skewed distributions}

From the analysis in Figure 6, there are 13 positively-skewed distributions, including Item 3, 6 and 9 which are the reverse items for this inventory. As such, these three items will be treated as the opposite and interpreted as negativelyskewed distributions. As a result, the authors have finalized that there are 10 positively-skewed distributions (Item 1, 2 , $4,5,6,7,8,9,10,12,14$, and 15) which proved that personal problems significantly affect teaching reflection practice among the respondents.

4.3.3 Negatively-skewed distributions

Based on the data in Table 6, there is originally one item (Item 11) which signifies a negatively-skewed distribution. However, the addition of Item 3, 6 and 9 in the list has made it four items in total. As a result, the authors has finalized that there are four negatively-skewed distributions (Item 3, 6, 9, and 11) which proved that personal problems do not affect teaching reflection practice among the respondents.

Table 6.15 Items of the Ideal PPRT Inventory

\begin{tabular}{|c|c|c|c|c|c|c|}
\hline My personal problems ... & TA $(\%)$ & A (\%) & $\mathrm{N}(\%)$ & $\mathrm{D}(\%)$ & $\begin{array}{l}\text { SD } \\
(\%)\end{array}$ & Affected \\
\hline $\begin{array}{l}\text { 1. Put me in an extremely difficult situation to } \\
\text { pay attention to students. }\end{array}$ & 24.4 & 55.6 & 11.1 & 8.9 & - & Yes \\
\hline $\begin{array}{l}\text { 2. Create a clear distance between me and my } \\
\text { students. }\end{array}$ & 40.0 & 44.4 & 4.4 & 6.7 & 4.4 & Yes \\
\hline 3. Affect my emotional judgments in school. & 44.4 & 35.5 & 11.1 & 4.4 & 4.4 & Yes \\
\hline $\begin{array}{l}\text { 4. Influence my decision-making in classes, } \\
\text { meetings, etc. }\end{array}$ & 35.5 & 42.2 & 4.4 & 15.6 & 2.2 & Yes \\
\hline $\begin{array}{l}\text { 5. Are a significant factor for me not doing my } \\
\text { teaching reflection. }\end{array}$ & 31.1 & 51.1 & 4.4 & 8.9 & 4.4 & Yes \\
\hline $\begin{array}{l}\text { 6. Trigger my argumentative nature with other } \\
\text { people in school. }\end{array}$ & 35.6 & 44.4 & 6.7 & 4.4 & 8.9 & Yes \\
\hline $\begin{array}{l}\text { 7. Are the reason for me not to conduct } \\
\text { consultations with students. }\end{array}$ & 42.2 & 40.0 & 4.4 & 4.4 & 8.9 & Yes \\
\hline 8. Set me off to neglect post-class reviews. & 40.0 & 42.2 & 2.2 & 6.7 & 8.9 & Yes \\
\hline $\begin{array}{l}\text { 9. Cause me to easily express my anger or } \\
\text { feeling of stress. }\end{array}$ & 44.4 & 35.6 & 11.1 & 6.7 & 2.2 & Yes \\
\hline $\begin{array}{l}\text { 10. Keep me back from carrying out discussions } \\
\text { regarding lessons in class. }\end{array}$ & 33.3 & 48.9 & 4.4 & 4.4 & 8.9 & Yes \\
\hline $\begin{array}{l}\text { 11. Restrain me from being supportive towards } \\
\text { my students' goals and ambitions. }\end{array}$ & - & - & 6.7 & 42.2 & 51.1 & No \\
\hline $\begin{array}{l}\text { 12. Discourage me from advising my students on } \\
\text { their academic performance outside } \\
\text { classrooms. }\end{array}$ & 46.7 & 37.8 & 2.2 & 4.4 & 8.9 & Yes \\
\hline $\begin{array}{l}\text { 13. Pose difficulties for me to understand other } \\
\text { people's point of view. }\end{array}$ & - & 6.7 & 62.2 & 24.4 & 6.7 & No \\
\hline $\begin{array}{l}\text { 14. Reduce my interest in spending time to make } \\
\text { extra notes for teaching lessons. }\end{array}$ & 37.8 & 44.4 & 4.4 & 8.9 & 4.4 & Yes \\
\hline $\begin{array}{l}\text { 15. Curb my intentions in improving my } \\
\text { students' academic performances. }\end{array}$ & 42.2 & 40.0 & 4.4 & 8.9 & 4.4 & Yes \\
\hline
\end{tabular}

*Indicators:

TA: Totally Agree $\quad$ A: Agree $\quad \mathbf{N}$ : Neutral $\quad$ D: Disagree $\quad$ SD: Strongly Disagree 
It has been confirmed that there is a significant relationship between personal problems and teaching reflection practice among secondary school English language teachers. 10 out of 15 items show positively-skewed distributions, which confirm the authors' theory that personal problems significantly affect teaching reflection practice.

\section{Conclusion}

\subsection{Implications for Future Research and Practice}

Based on the responses gathered from the selected 45 English language teachers, it is clear that personal problems faced by them have definitely affected their teaching reflection practice. That means it may also affect other teachers in the same district or even in other states and nations. However, focusing on only English language teachers, their teaching impact on students are critical because in Malaysia' education system, English is one of the four compulsory subjects in schools (Ministry of Education Malaysia, 2012); from primary to tertiary levels. Hence, all students are at risk of being affected if the teachers could not solve their personal problems. In order to resolve this matter quickly, all teachers in learning institutions must be aware of the consequences and take necessary actions before it gets worse. Administrations can first provide a medium for teachers to express their problems and later conduct or sponsor not just regular functional trainings, but also specific professional development courses to further curb this phenomenon. By time, higher levels of administrations, such as the district education office or Ministry of Education may conduct researches on a bigger scale on different aspects of problems faced by teachers, and implement changes whilst taking teachers' responds and feedbacks into consideration.

\subsection{Recommendations}

Clearly, teachers' relationship with their spouses or partners can affect their professional teaching performance in schools because it has been proven that relationship problems such as divorce attitudes, parental marital status and specific relationship scenarios can generate negative behaviours and greater conflicts towards their students (Riggio \& Fite, 2006). For this particular problem, it has recorded the highest number of teachers suffering from it $(60 \%)$. Hence, it is highly recommended that if they are still not married, then they should get married. For the affected married teachers, they must start evaluating their relationship with their partner. These teachers might not be aware of the marriage problem checklists or questionnaires that have been introduced since many years ago up until today. Affected teachers may use them as a primary guidance and they are also readily available on the Internet and have been categorized for both pre-marital and married. Some of them are 'Marriage Test' by Kerby Anderson (2001), 'The Communication Pattern Questionnaire' (1984), 'Divorce Triggers' by Lisa Grace Paul (2010), and 'Pre-Marriage Checklist' by Dr. Clyde Narramore (2012). In fact, marriage consultancy is quite common everywhere, including Malaysia (Mohd. Noor, 2010).

Researches have also shown that Malaysian government provides fairly low salaries to all teachers in government schools ( (Abdullah, Uli, \& Parasuraman, 2009) and (Munaf, 2009)); even the Malaysian government admits that notion by proposing recommendations to review and revise teachers' salary scales to suit with the continuous hikes in prices of goods and necessities (Official Portal of Economic Planning Unit, 2002). In addition to their salary, they may also have problems adjusting or managing their incomes with cost of living, personal transport, lifestyle budget, addition in family members, etc. From the second highest statistics gained in this matter $(33.3 \%)$, it is suggested that these teachers find help from financial experts or attend courses on how to manage money effectively. They may have to sacrifice some unnecessary or unimportant spending such as on trends and social engagements which may require additional clothing, gadgets, and other personal items. For those who are living in high-living-cost areas or big towns such as Kuala Lumpur and Johor Bahru, they might want to consider moving into another living area in the nearest district with cheaper cost of living rates compared to their current ones. Of course, these teachers are also recommended to have part-time jobs such as tuition classes, editing, or proofreading which not only serve as additional income, but also sharpening their teaching or linguistic skills.

With $20 \%$ and below in terms of the statistics respectively, teachers still need to be aware that aside from financial and family issues, the personal problem(s) may as well come from the workplace itself. From the moment teachers came to their respective schools on the first day, total adaptation process must already be in process. Adding to that, appointed mentor or advisor must be the first reference for any matter regarding their official and unofficial duties in schools. This is because a research in Tawau, Sabah has shown that secondary school teachers in general are dissatisfied with their work itself, co-workers, supervision, and working conditions (Abdullah, Uli, \& Parasuraman, 2009). Affected teachers are advised to be aware of their professionalism whenever they are dealing with official matters, such as meetings, undergoing supervisions, and teaching in classrooms. Light moods and jokes are totally acceptable as long as they keep it within the professional ethics boundaries. For example in some schools, ranks may be a distinct boundary between teachers and administration. Sometimes, they even have to be aware of their peers or colleagues in the same department as some of them would be more senior compared to the others. Teachers are also expected to be able to control their emotions and behaviours inside and outside classrooms.

From the administration's perspective, they should conduct continuous functional trainings and sponsor professional development courses for the teachers to ensure their teaching performance improves by time or even maintains at the highest level for as long as they working there. School administrators are also responsible for providing optimum working environments to ensure that the teaching-learning process can be conducted smoothly for both teachers and students. This can be done with proper high involvement management and the implementation of enriched job design (Wood, Van Veldhoven, Croon, \& de Menezes, 2012) which allows flexibility for teachers in their work. Therefore, teachers are always welcomed to modify their surroundings to increase the learning mood in and outside classrooms as 
long as they keep it educational, relevant, and beneficial for all parties in the school. However, teachers sometimes have to bear with the insufficient teaching materials or unusable facilities in their schools because of the school's limited budget, such as in rural areas. In Uganda, researchers have shown that the academics there are still satisfied with their courses despite having less equipment to use such as access to computers and relaxation facilities (Ssesanga \& Garrett, 2005). With the idea of "doing more with less", they also indicated that the academics' intrinsic motivation has been contributing towards their increasing performance of teaching and research despite experiencing shortage of stuffs to use during teaching.

\section{References}

Abdullah, M. M., Uli, J., \& Parasuraman, B. (2009). Job satisfaction among secondary school teachers. Jurnal Kemanusiaan, 11-18.

Ary, D., Jacobs, L. C., \& Sorensen, C. (2006). Introduction to Research in Education. Belmont: Wadsworth.

Cerit, Y. (2009). The Effects of Servant Leadership Behaviours of School Principals on Teachers' Job Satisfaction. Educational Management Administration \& Leadership, 600-623.

Creswell, J. W. (2008). Educational Research. New Jersey: Pearson Education Inc.

Goris, J. R., Vaught, B. C., \& Pettit, J. D. (2003). Effects of Trust in Superiors and Influence of Superiors on the Association between Individual-Job Congruence and Job Performance/Satisfaction. Journal of Business and Psychology, 327-343.

Masilamani, R., Darus, A., Ting, A. S., Ali, R., Awang Mahmud, A. B., \& David, K. (2011). Asia-Pacific Journal of Public Health. Salivary Biomarkers of Stress Among Teachers in an Urban Setting, 278-287.

Mattaliano, A. P. (1979). When Personal Problems Interfere with Teachers' Effectiveness. Educational Leadership, 427-429.

Merriam, S. B., \& Mohamad, M. (2000). How Cultural Values Shape Learning in Older Adulthood: The Case of Malaysia. Adult Learning Quarterly, 45-63.

Ministry of Education Malaysia. (2012). Retrieved from http://www.moe.gov.my/v/

Mohd. Noor, S. Z. (2010, October 30). Portal Rasmi Jabatan Kemajuan Islam Malaysia. Retrieved May 24, 2012, from JAKIM: http://www.islam.gov.my/sites/default/files/consultancy_-_ways_to_solve_family_issues.pdf

Munaf, S. (2009). Motivation, Performance and Satisfaction Among University Teachers: Comparing Public and Private Teachers: Comparing Public and Private. South Asian Journal of Management, 7-28.

Nakata, Y. (2010). Improving the Classroom Language Proficiency of Non-native Teachers of English: What and How? RELC Journal, 16.

Ng, T. W., Sorensen, K. L., \& Yim, F. H. (2009). Does the Job Satisfaction--Job Performance Relationship Vary Across Cultures? Journal of Cross-Cultural Psychology, 761-796.

Official Portal of Economic Planning Unit. (2002, October 18). Retrieved May 24, 2012, from Prime Minister's Department http://www.epu.gov.my/html/themes/epu/images/common/pdf/publication/knowledge_based/CHAPTER_3.pdf Malaysia:

Rajaratenam, R. M. (2012, March 11). New Straits Times. Retrieved March 18, 2012, from http://www.nst.com.my/opinion/letters-to-the-editor/exam-oriented-system-evaluate-students-on-all-their-abilities

Riggio, H. R., \& Fite, J. E. (2006). Attitudes Toward Divorce: Embeddedness and Outcomes in Personal Relationships. Journal of Applied Social Psychology, 2935-2962.

Schleicher, A. (2011). Lessons from the World on Effective Teaching and Learning Environments. Journal of Teacher Education, 202-221.

Shapira-Lishchinsky, O., \& Rosenblatt, Z. (2009). Organizational Ethics and Teachers' Intent to Leave: An Integrative Approach. Educational Administration Quarterly, 725-758.

Ssesanga, K., \& Garrett, R. M. (2005). Job Satisfaction of University Academics: Perspectives from Uganda. Higher Education, 33-56.

The Economic Planning Unit. (2010). TENTH MALAYSIA PLAN 2011-2015. Putrajaya: Prime Minister's Department Malaysia.

Vacilotto, S., \& Cummings, R. (2007). Peer coaching in TEFL/TESL programmes. ELT Journal, 153-160.

Veenman, S. (1984). Perceived Problems of Beginning Teachers. Review of Educational Research, 143-178.

Wood, S., Van Veldhoven, M., Croon, M., \& de Menezes, L. M. (2012). Enriched job design, high involvement management and organizational performance: The mediating roles of job satisfaction and well-being. Human Relations, 419-446. 